\title{
Nondestructive Testing Technology and Quality Management of Roads and Bridges
}

\author{
Weiwei Li*, Yiguo Xue, Yanliang Du, Youguo Wang \\ Shandong University, Jinan, China \\ Email: vivienli0914@icloud.com
}

\begin{abstract}
The purpose of this study is to understand the current nondestructive testing technology in roads and bridges and to explore the quality management measures. In this study, firstly, the most commonly used nondestructive testing technology, that is, ultrasonic nondestructive testing technology, is introduced. And the common testing methods are listed and the main influencing factors and precautions are analyzed. Secondly, the road and bridge engineering quality management methods and control measures are put forward, that is, develop a scientific quality management plan, improve the quality management awareness, and establish the construction quality management and control measures. The results show that this study can provide a reliable basis for taking measures in advance and formulating effective reinforcement plans for roads and bridges with hidden safety hazards and objectively determining whether roads and bridges need to be dismantled. Therefore, this study has a certain practical significance and provides a certain reference for the safe operation of current road and bridge projects.
\end{abstract}

Keywords: Nondestructive testing technology, quality management, roads and bridges, control measures, safety.

\section{Introduction}

The performance and durability of road and bridge structures are mainly determined by many factors such as design, construction and the quality of materials used $[1,2]$. Due to certain deficiencies in design, construction, and materials, these defects can cause inherent weaknesses in roads and bridge structures. In addition, roads and bridges will suffer from inevitable man-made damage and various natural erosion in the process of operation and use, resulting in acquired diseases $[3,4,5]$. The adverse effects of congenital defects and acquired diseases are often combined. If the critical combination of load and external force is encountered again, it is easy to cause unforeseeable damage to roads and bridges $[6,7$, 8]. One or a few local damages in the road and bridge structure may have a chain reaction, affecting more locations, developing into greater damage, and even endangering the safety of the road and bridge. Therefore, in order to ensure the built roads and bridges in good operation status and normal use function, it is necessary to timely detect the early disease and take maintenance measures before the occurrence of greater damage, so as to control the development of the disease or remove the disease. To achieve this goal, roads and bridges must be inspected and tested. In China, a large number of diseases and damages have occurred in various roads and bridges $[9,10]$. Therefore, the establishment of detection and evaluation system for old bridges and diseased roads and bridges has become an urgent need for road and bridge management departments, and has gradually become a research hotspot in the field of roads and bridges.

The testing of road and bridge has become one of the hot topics in the current engineering field, and ultrasonic nondestructive testing is an important part of road and bridge testing [11, 12]. In this study, the ultrasonic nondestructive testing technology is mainly introduced and some suggestions on quality management are put forward, hoping to provide some references for the prevention and treatment of road and bridge diseases. 


\section{Ultrasonic Nondestructive Testing Technology}

\subsection{Flow of Ultrasonic Nondestructive Testing}

Similar to the flow of other nondestructive testing technologies, the flow of ultrasonic nondestructive testing technology is as follows.

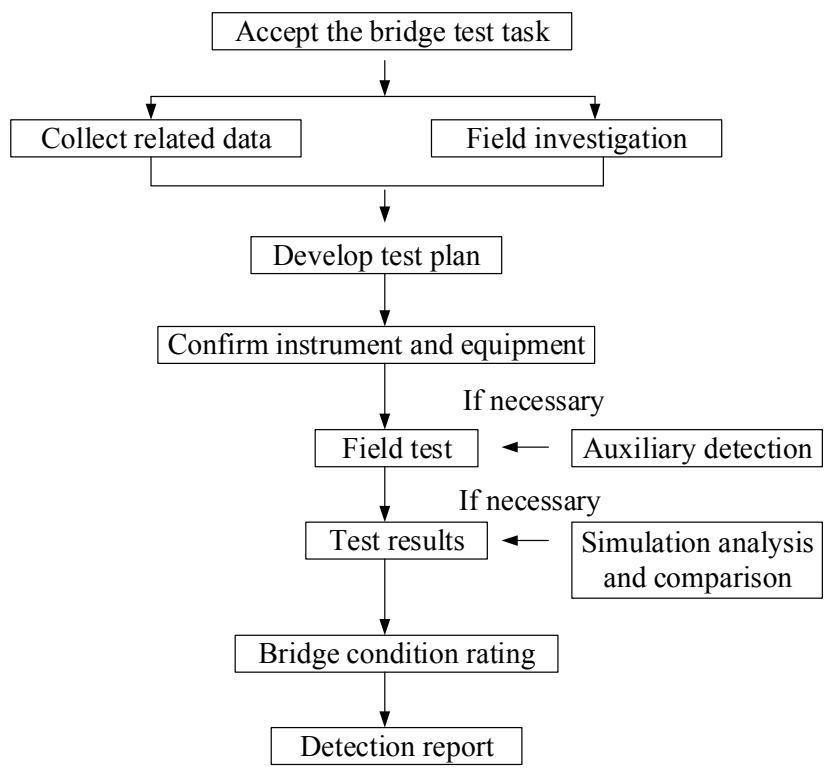

Figure 1. Flow chart of ultrasonic nondestructive testing

\subsection{Common Test Methods}

Generally, the specific test method is determined according to the shape, size and environment of the structure or component under test. Common test methods can be roughly divided into the following:

First, the plane detection method. Paired detection method: a pair of transmitting (T) and receiving (R) transducers are respectively coupled to two parallel surfaces of the component under test, and the axes of the two transducers are located on the same straight line. The method is suitable for the members with two pairs of parallel surfaces. Oblique detection method: a pair of $\mathrm{T}$ and $\mathrm{R}$ transducers is coupled to two surfaces of the component under test, and the axes of the two transducers are not in the same line. The method is suitable for components with a pair of parallel or two adjacent surfaces for testing. Flat detection method: a pair of $\mathrm{T}$ and $\mathrm{R}$ transducers is placed on the same surface of the tested component for testing. This method is suitable for structures with only one surface available for testing.

Second, drilling or embedded pipe detection method. Paired detection in the hole: a pair of $\mathrm{T}$ and $\mathrm{R}$ transducers are respectively placed in two corresponding boreholes (or embedded pipes) of the structure under test and tested at the same height. This method is suitable for the general measurement of largevolume concrete structures. Oblique detection in the hole: a pair of $\mathrm{T}$ and $\mathrm{R}$ transducers are respectively placed in two corresponding boreholes (embedded pipes) of the structure under test, but the two transducers are not at the same height but maintain a certain height difference for detection. This method is suitable for the fine measurement of mass concrete structure to further find out the location and range of defects between the two test holes. Flat detection in the hole: put a pair of $\mathrm{T}$ and $\mathrm{R}$ transducers into the same borehole of the structure under test, and move synchronously with a certain height difference for detection. This method is suitable for the fine measurement of mass concrete structure to further find out the location and range of defects near a certain borehole. Radial vibration transducer is used for drilling or embedded pipe detection, as show in figure 2 and figure 3 .

Third, hybrid detection method. Hybrid testing uses a thickness vibrating transducer and a radial vibrating transducer. A radial vibration transducer is placed in the borehole, and a thickness vibration 
transducer is coupled to the surface of the measured structure parallel to the axis of the borehole for paired measurement and oblique measurement. This method is suitable for the concrete structure with small section size or no more boreholes.

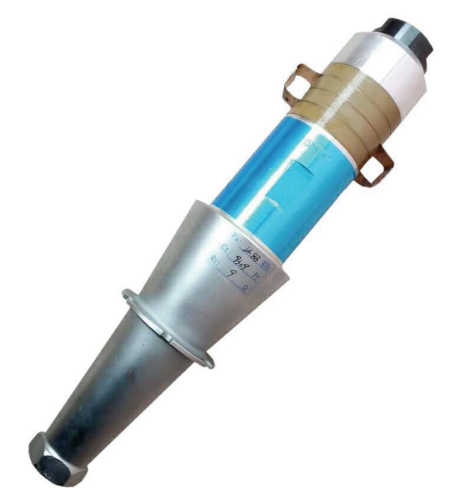

Figure 2. The picture of transducer

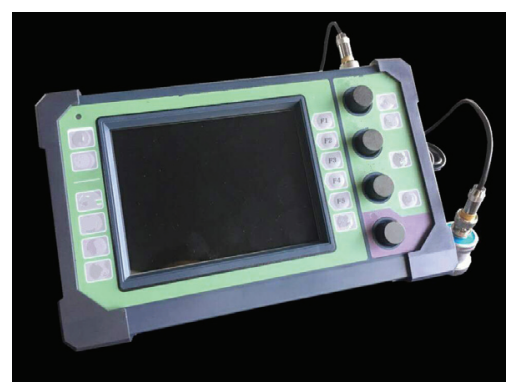

Figure 3. The picture of Instrument for nondestructive testing

\subsection{Main Influencing Factors and Precautions During Testing}

Whether it is to detect the strength or defect of road and bridge concrete, it will be affected by many factors. According to the research of domestic and foreign scientists and the experience in the actual testing process, these influencing factors and corresponding precautions are summarized into the following aspects:

First, the effect of lateral size effects. Attention must be paid to the effect of the transverse size of the specimen when measuring the sound velocity. Usually, the longitudinal wave velocity is measured in an infinite medium. As the transverse size of the specimen decreases, the compressional wave velocity may change to the sound velocity of the rod or plate or the surface wave velocity, that is, the sound velocity is smaller than that of the infinite medium. When the horizontal minimum dimension $\mathrm{d} \geqslant 2 \mathrm{~A}(2$ is the wavelength), the propagation velocity is equivalent to the wave velocity value in the bulk; when a $<\mathrm{d}$ $<22$, the propagation velocity decreases by $2.5 \%$; when $0.22<\mathrm{d}<2$, the propagation velocity changes greatly, about $6 \% \sim 7 \%$, in this case, the estimated error can reach $30 \% \sim 40 \%$, which is not allowed.

Table 1. Selection of the minimum section size and probe natural frequency for different ranging

\begin{tabular}{ccc}
\hline Probe penetration length $(\mathrm{mm})$ & Probe natural frequency $(\mathrm{Hz})$ & Minimum transverse dimension of concrete $(\mathrm{mm})$ \\
\hline $100-70$ & $\geqslant 60$ & 70 \\
$200-1500$ & $\geqslant 40$ & 150 \\
$>1500$ & $\geqslant 20$ & 300 \\
\hline
\end{tabular}

Second, the influence of temperature and humidity. When the concrete is at an ambient temperature of $5{ }^{\circ} \mathrm{C} \sim 30{ }^{\circ} \mathrm{C}$, the speed reduction caused by the temperature rise is not large, and the ultrasonic 
sound velocity reduction value caused by the temperature can be neglected. When the environment is in the range of $40{ }^{\circ} \mathrm{C} \sim 60{ }^{\circ} \mathrm{C}$, the pulse speed value is reduced by about $5 \%$, which may be due to the increase of micro cracks inside the concrete. When the temperature is below $0{ }^{\circ} \mathrm{C}$, the pulse speed is increased due to free water freezing in the concrete (the ultrasonic wave speed is $145 \mathrm{~km} / \mathrm{s}$ in free water and $3.50 \mathrm{~km} / \mathrm{s}$ in ice).

The influence of humidity on the propagation velocity of ultrasonic wave can be explained as the concrete curing in water has a higher degree of hydration and forms a large number of hydration products. The reflection of the propagation velocity of ultrasonic wave on this product is greater than that of the concrete hardening in air. In addition, water curing concrete penetrates and fills the pores of concrete. Since ultrasonic propagation velocity in water is $1.45 \mathrm{~km} / \mathrm{s}$ and $0.34 \mathrm{~km} / \mathrm{s}$ in air. Therefore, concrete cured in water has a much higher ultrasonic propagation velocity than that cured in air, even covering the influence of increased sound velocity with the increase of concrete strength.

Third, the effect of water-cement ratio and cement consumption. The compressive strength of concrete is closely related to the water-cement ratio. As the water-cement ratio decreases, the strength, compactness and elastic properties of concrete increase correspondingly, and the propagation speed of ultrasonic pulse in concrete increases correspondingly. Otherwise, the velocity of ultrasonic pulse decreases with the increase of water-cement ratio. At the same time, the change of cement content actually changes the composition of the ratio of aggregate binder. Under the same concrete strength, when the amount of coarse aggregate remains unchanged, the higher the cement content is, the lower the ultrasonic velocity will be.

Fourth, the effect of moisture. The sound velocity and acoustic impedance of water are many times larger than the sound velocity and acoustic impedance of air. If the air in the concrete defect is replaced by water, most of the pulse wave is no longer reflected and diffracted at the defect interface, but propagated directly through the defect from the water coupling layer to the receiving transducer, so that the difference in sound velocity, amplitude and frequency measurement of the concrete with or without defects is not obvious, which brings difficulties to defect testing and judgment. In the defect detection, the concrete should be in a natural dry state, especially in the concrete crack detection, to ensure that there is no water in the middle of the crack.

\section{Quality Management and Control Measures for Road and Bridge Engineering}

\subsection{Develop the Scientific Quality Management Plan}

It should understand the basic outline of the project, collect relevant information about the project, and set quality objectives. In addition, it should break down the quality management objectives and formulate and issue the implementation quality control plan. Among them, the contents of the quality management plan are as follows: understand the internal and external conditions and environment of road and bridge construction, and make a specific analysis of these conditions, including the agreement content and legal factors in the process of project construction; establish corresponding quality objectives in the process of signing the project engineering agreement and constitute the project engineering process; define corresponding hardware resources, project quality assurance technology, project engineering materials, quality management plan and project engineering testing process, and formulate corresponding measures.

\subsection{Improve Quality Management Awareness}

The construction of roads and bridges requires the establishment of corresponding management system, and it also needs to be carried out according to certain procedures, which is an important part of the project construction process. In the process of project construction, it is necessary to improve the quality management awareness of project construction and management personnel, which is also the basis of the road and bridge engineering project department. Only by improving the construction quality, can the project construction be guaranteed. It should strengthen quality management training, for example, organizing professional skills training. According to the project construction process and various forms of 
construction operations, relevant skills training is provided for road and bridge projects, and technical personnel also need to learn professional skills.

Secondly, it should formulate the quality assessment system of the actual construction. In the process of construction, it is necessary to establish a quality assessment system for actual construction, and evaluate all project construction personnel according to this assessment system. If some staff members are irresponsible, corresponding punishment measures should be taken. For some excellent staff, certain rewards should be given to provide maximum spiritual guidance for construction workers. Construction personnel need to analyze the problems in the process of project construction according to the quality management system, carry out a specific analysis of this problem, adhere to the people-oriented principle, ensure the quality of the project, and record the project construction problems and the corresponding measures to strengthen management.

\subsection{Establish Construction Quality Management and Control Measures}

Firstly, establish the construction quality management organization of road and bridge engineering, as shown in the figure below.

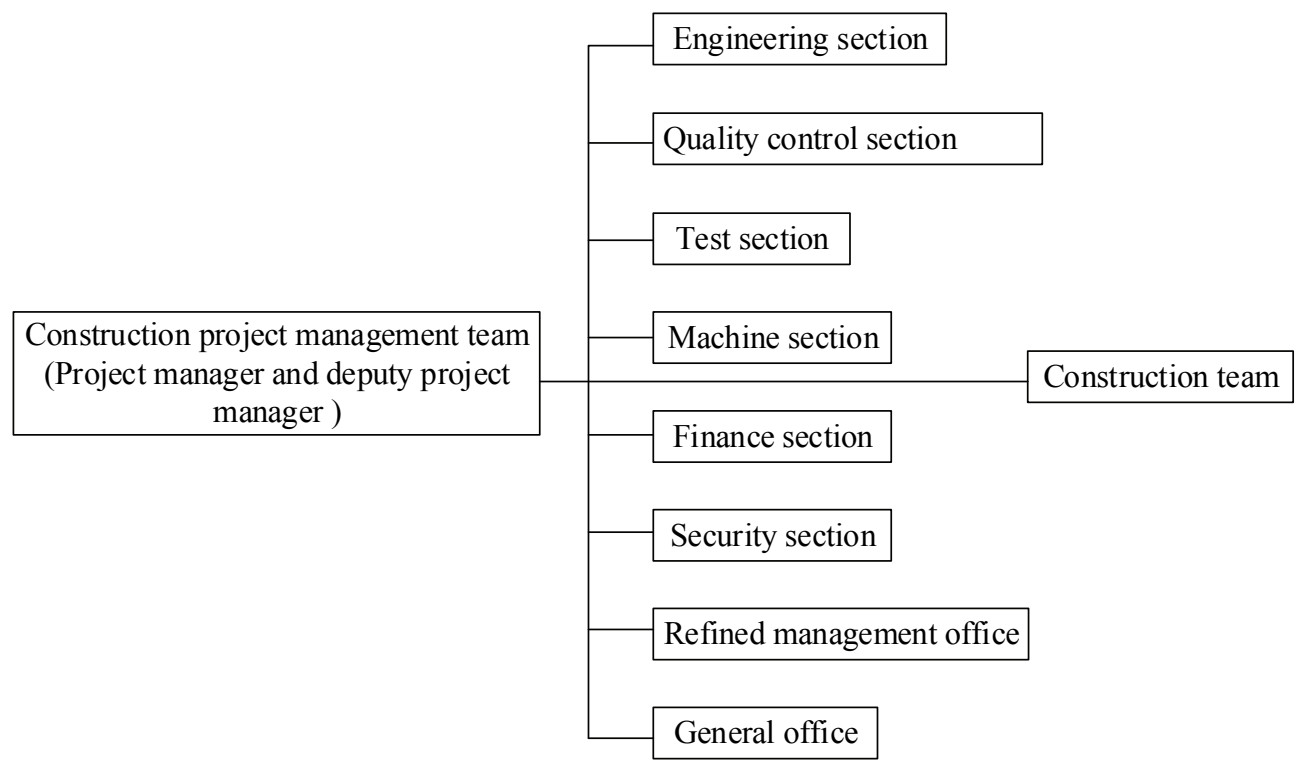

Figure 4. Project management organization chart for road and bridge engineering

Second, improve the quality management system. Define responsibility. It mainly refers to strengthening quality management by forming a group. In this group, project managers and technical leaders are important components, which are responsible for different construction quality components. The main task of the team is to strengthen quality management, formulate construction plans for the construction organization, inspect each link, analyze the problems in the construction process, and take measures to correct these construction problems. Develop a corresponding responsibility system for quality objectives. It should make adjustments based on actual problems, clarify the objectives of each department, and develop appropriate quality targets to guide staff actions. At the same time, a certain performance system should be set up to improve the enthusiasm and quality awareness of the staff and ensure the quality of the project construction products. Clear assignment distribution. Scientific and reasonable division of labor needs to strengthen the project quality management. Only by rationally dividing the project, the cohesiveness of the employees can be improved, and the important role of the talents can be fully utilized. 


\section{Conclusion}

In this study, the ultrasonic nondestructive testing technology of roads and bridges is mainly introduced. Secondly, the problems in the process of road and bridge project construction are analysed, and the corresponding solutions to these problems are put forward. It mainly includes making scientific quality management plan, strengthening quality management consciousness and establishing construction quality management measures. The above measures are intended to formulate the corresponding scientific management plan for the project, strengthen the project assessment management from the perspective of "people", and enhance the quality management awareness of the staff. When taking corresponding quality management measures, in addition to the management organization and management system, environmental conditions in the process of project construction should also be considered, and the quality control in each stage of the project construction process should be strengthened. It is of practical significance to carry out research on the diseases of concrete roads and bridges, the development of non-destructive testing equipment and development of practical testing and evaluation standards for roads and bridges. The above studies can provide a reliable basis for taking measures in advance and formulating effective reinforcement plans for roads and bridges with hidden safety hazards and objectively determining whether roads and bridges need to be dismantled. Therefore, it is of great significance to carry out this research to effectively reduce the accident probability of roads and bridges, effectively utilize public facilities, save social resources and protect the natural environment.

\section{References}

1. Ivashov, S. I., Bugaev, A. S., Zhuravlev, A. V., Razevig, V. V., Chizh, M. A., \& Ivashov, A. I. (2018). Holographic subsurface radar technique for nondestructive testing of dielectric structures. Technical Physics, $63(2), 260-267$.

2. Qin, J., Liu, X., Van, K. D. A., \& Cui, G. (2018). The study of wood knots using acoustic nondestructive testing methods. Ultrasonics, 88(01), 43.

3. Matysík, M., Carbol, L., Chobola, Z., \& Plšková, I. (2018). Nonlinear acoustic spectroscopy method for nondestructive testing of thermally damaged concrete. Solid State Phenomena, 276, 128-133.

4. Kim, H., Kang, D., Oh, S. J., \& Joo, C. (2018). Nondestructive evaluation on dispersion of steel fibers in uhpc using thz electromagnetic waves. Construction \& Building Materials, 172, 293-299.

5. Potapov, A. I., \& Makhov, V. E. (2018). Methods for nondestructive testing and diagnostics of durability of articles made of polymer composite materials. Russian Journal of Nondestructive Testing, 54(3), 151-163.

6. Moiseykin, E. V., Nikiforov, S. V., Ust'Yantsev, Y. G., Khokhlov, K. O., \& Polyakova, K. A. (2018). A device for thermal treatment of luminescence ionizing-radiation detectors intended for radiation nondestructive testing. Russian Journal of Nondestructive Testing, 54(11), 792-796.

7. Terzioglu, T., Karthik, M. M., Hurlebaus, S., Hueste, M. B. D., Maack, S., \& Woestmann, J., et al. (2018). Nondestructive evaluation of grout defects in internal tendons of post-tensioned girders. Ndt \& E International, 99, 23-35.

8. Harara, W., \& Altahan, A. (2018). Attempt towards the replacement of radiography with phased array ultrasonic testing of steel plate welded joints performed on bridges and other applications. Russian Journal of Nondestructive Testing, 54(5), 335-344.

9. Rocha, J. H. A., Póvoas, Y. V., \& Santos, C. F. (2018). Detection of delaminations in sunlight-unexposed concrete elements of bridges using infrared thermography. Journal of Nondestructive Evaluation, 38(1), 8.

10. Bazulin, E. G., Goncharsky, A. V., Romanov, S. Y., \& Seryozhnikov, S. Y. (2018). Parallel cpu- and gpualgorithms for inverse problems in nondestructive testing. Lobachevskii Journal of Mathematics, 39(4), 486-493.

11. Koshekov, K. T., Klikushin, Y. N., Kashevkin, A. A., Latypov, S. I., Sof'Ina, N. N., \& Savostina, G. V., et al. (2018). An intelligent system for vibrodiagnostics of oil and gas equipment. Russian Journal of Nondestructive Testing, 54(4), 249-259.

12. Chróścielewski, J., Miśkiewicz, M., Łukasz Pyrzowski, Rucka, M., Sobczyk, B., \& Wilde, K. (2018). Modal properties identification of a novel sandwich footbridge - comparison of measured dynamic response and fea. Composites Part B Engineering, 151, 245-255. 